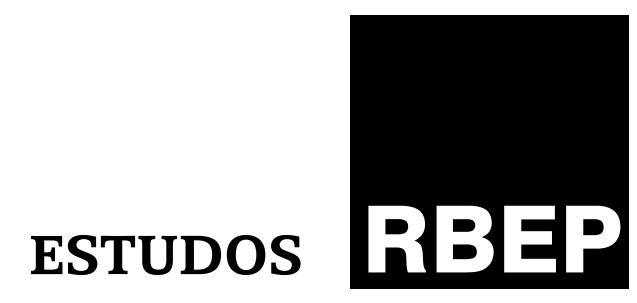

\title{
Concepções de natureza e sensibilidade ambiental nos livros didáticos de História Natural $(1934-1971)^{*}$
}

Carlos Renato Carola

Gladir Silva Cabral

\section{Resumo}

Teve por objetivo perceber e identificar sensibilidades ambientais e concepções de natureza cristalizadas nos manuais didáticos de História Natural que circularam pelas escolas brasileiras no período de 1934 a 1971. O trabalho situa-se no campo de pesquisa da História da Educação e, especificamente, foca-se na história de uma disciplina escolar. Foram identificados e catalogados 77 manuais didáticos de ensino de História Natural. Em termos mais específicos, procuramos perceber se os livros assimilaram o pensamento ecológico difundido por diversos intelectuais e cientistas que assumiram a causa da "proteção à natureza" no período histórico investigado. Os livros identificados e analisados foram encontrados na Biblioteca Nacional/Rio de Janeiro, na Biblioteca do Livro Didático da Faculdade de Educação da Universidade de São Paulo (USP), em bibliotecas de escolas públicas e em diversos sites. A metodologia de pesquisa fundamentou-se no método histórico, com orientações teóricometodológicas de História da Educação e História Ambiental.

Palavras-chaves: História Natural; sensibilidade ambiental; concepções de natureza; livros didáticos. 


\section{Abstract \\ Conceptions of nature and environmental sensitivity in the textbooks of Natural History (1934-1971)}

We aimed at understanding and identifying environmental sensitivities and conceptions of nature crystallized in textbooks of Natural History that circulated in Brazilian schools from 1934 to 1971. The work is located in the search field of History of Education and is specifically focused on the story of a school subject. 77 Natural History textbooks were selected and cataloged. Specifically speaking, we seek to understand if the books assimilated widespread ecological thoughts by many intellectuals and scientists who took the question of "nature protection" in the historical period investigated. The books identified and analyzed were found at the National Library (Rio de Janeiro), at the Library of Textbooks College of Education at the University of São Paulo (USP), in public schools and libraries in several sites available on the internet. The research methodology was based on the historical method of investigation, and theoretical and methodological approaches for the History of Education History and Environment.

Keywords: Natural History; environmental sensitivity; conceptions of nature; textbooks.

\section{Introdução}

Objeto de "múltiplas facetas", o livro didático pode ser pesquisado como produto cultural, mercadoria ligada ao mundo editorial, suporte de conhecimentos escolares propostos pelas disciplinas escolares, ou, ainda, como veículo de um sistema de valores, de uma ideologia ou de uma cultura. Representa um material ímpar para pesquisas de diferentes áreas, como Pedagogia, História, Ciências Políticas e Econômicas, Sociologia, Linguística entre outras. (Biblioteca..., [s.d.]).

Pesquisas realizadas no Brasil nas últimas décadas comprovaram convincentemente a relevância dos livros escolares como objeto de pesquisa no campo da História da Educação. No passado como no presente, os livros didáticos fazem parte do cotidiano escolar. Como sugere Circe Bittencourt (2003), o livro didático possui múltiplas facetas, é apreendido de formas distintas, incorpora sistemas de valores e ideologias das sociedades. Além disso, é também um instrumento de difusão de conhecimento das disciplinas escolares e especialidades da ciência. Circe Bittencourt define "disciplina escolar" como uma produção didática proveniente de relações complexas entre conhecimento científico e conhecimento escolar. Os livros didáticos de disciplinas escolares 
desempenham a função de difusão do conhecimento científico, adaptado numa linguagem acessível para professores e alunos do ambiente escolar. Apesar de haver certa dependência da cultura acadêmica, uma vez que o conteúdo é organizado a partir de uma produção científica, as estratégias pedagógicas e orientações didáticas são definidas com base na cultura escolar e em teorias de educação e aprendizagem. Assim, os manuais de ensino de disciplinas escolares possuem objetivos e necessidades distintas da ciência de referência (Bittencourt, 2003).

Segundo Choppin (2004, p. 551), "no Brasil os livros didáticos correspondiam, no início do século XX, a dois terços dos livros publicados e representavam, ainda em 1996, aproximadamente $61 \%$ da produção nacional". A definição desse novo "objeto" de pesquisa ainda é problemática, mas com as pesquisas realizadas em diversos países já é possível fazer um balanço geral do estado da arte e caracterizar de forma mais segura definições e tipologias quanto aos objetivos, à forma e ao conteúdo dos livros escolares.

Nesse sentido, adotamos referências conceituais de pesquisas já existentes. Por manuais didáticos, por exemplo, consideramos os livros que "são concebidos na intenção, mais ou menos explícita ou manifesta segundo as épocas, de servir de suporte escrito ao ensino de uma disciplina no seio de uma instituição escolar" (Choppin, 1992 apud Batista; Galvão; Klinke, 2002, p. 33). No início do século 20, o papel dos livros escolares ainda não estava seguramente definido, mas aos poucos ele foi se inserindo na rotina escolar "com a criação progressiva de estruturas educativas estáveis, uniformes e cada vez mais diversificadas" (p. 33). Com a difusão dos manuais, as disciplinas escolares também são valorizadas, pois "as publicações que gravitam em torno deles (livros ou guias para o professor, antologias de documentos, cadernos ou fichários de exercícios, léxicos, antologias de atividades) se destinam sempre a uma disciplina, a um nível, a uma série ou a um grau e se referem a um programa preciso" (p. 33). Assim, "o manual apresenta, então, ao aluno, o conteúdo desse programa, segundo uma progressão claramente definida, e sob a forma de lições ou unidades. Essas obras são sempre concebidas para um uso tanto coletivo (em sala de aula, sob a direção do professor) e individual (em casa)" (p. 33).

Manuais didáticos e disciplina escolar são objetos de observação deste trabalho. O artigo apresenta o resultado de um projeto de pesquisa que teve por objetivo perceber e identificar sensibilidades ambientais e concepções de natureza cristalizadas nos manuais didáticos de História Natural que circularam pelas escolas brasileiras no período de 1934 a 1971. Nesse período, os dados estatísticos oficiais indicam um crescimento acelerado de número de escolas, número de alunos matriculados e produção de livros didáticos. De 1920 a 1970, o número de matrículas no ensino primário subiu de cerca de um milhão para 14 milhões de crianças escolares; e no ensino médio, de cerca de 110 mil para 5 milhões. Na época, a estrutura do sistema nacional de ensino era organizada em quatro níveis: ensino pré-primário, com duração de três anos e faixa etária de 
4 a 6 anos; ensino primário, com duração de quatro anos e faixa etária regular de 7 a 10 anos; ensino médio (ginásio e colégio), com duração de sete anos e faixa etária regular de 11 a 17 anos; e ensino superior, com durabilidade variável e idade acima dos 18. O ensino médio era subdividido em dois ciclos, o ginasial, com quatro anos, e o colegial, com três. Ambos constituíam o ensino secundário e o ensino técnico profissionalizante (Brasil. MEC, 2002, p. 23-25).

A metodologia de pesquisa fundamentou-se no método histórico, com orientações teórico-metodológicas de História da Educação e História Ambiental, e foca-se na história de uma disciplina escolar. Foram identificados e catalogados 77 manuais didáticos de ensino de História Natural. Em termos mais específicos, procuramos perceber se os livros assimilaram o pensamento ecológico difundido por diversos intelectuais e cientistas que assumiram a causa da "proteção à natureza" no período em questão. Os livros identificados e analisados foram encontrados na Biblioteca Nacional do Rio de Janeiro, na Biblioteca do Livro Didático da Faculdade de Educação da Universidade de São Paulo (USP), em bibliotecas de escolas públicas e nos sites:

- Acervo Histórico do Livro Escolar (AHLE) das antigas escolas públicas infantis da cidade de São Paulo, organizado pela professora Dra Azilde Andreotti (http://acervohistoricodolivroescolar. blogspot.com/);

- acervo digital dos livreiros cadastrados na Estante Virtual (http:// www.estantevirtual.com.br/);

- acervo digital do Centro de Referência em Educação Mário Covas (http://www.crmariocovas.sp.gov.br/);

- coleção de livros didáticos do Centro de Documentação e Apoio à Pesquisa em História da Educação (CDAPH), da Universidade de São Francisco (http://www.usf.edu.br/cdaph/FreeComponent866content1120.shtml);

- Nosthalgia - Coleções, Álbuns de Figurinhas (http://www.nosthalgia.com.br);

- Mania de Colecionador - Coleção de Álbuns de Figurinhas (http:// www.maniadecolecionador.com.br/);

- Mercado Livre (http://lista.mercadolivre.com.br/historia-natural).

Os marcos do recorte temporal lembram eventos significativos para o desenvolvimento de uma nova sensibilidade ambiental. No Brasil, no início da década de 1930, em meio à euforia dos discursos de modernização e industrialização, consolida-se uma corrente de pensamento com uma sensibilidade ambiental incômoda para as elites da oligarquia rural e para as elites liberais que aderiram ao projeto desenvolvimentista. Em abril de 1934, realiza-se no Rio de Janeiro a primeira Conferência Brasileira de Proteção à Natureza e, em julho do mesmo ano, o presidente Getúlio Vargas anuncia a publicação do Código de Águas Brasileiro. No mesmo período também se aprova o Código Florestal, o Código de Caça 
e Pesca e o Código de Minas. O conjunto dessas leis configura uma das fases de desenvolvimento da legislação ambiental brasileira. Em 1971, José Lutzeberger lidera a criação da Associação Gaúcha de Proteção ao Ambiente Natural (Agapan). No ano seguinte, em 1972, ocorre em Estocolmo, na Suécia, a primeira Conferência Mundial sobre Meio Ambiente e Desenvolvimento, preparada pela Organização das Nações Unidas (ONU). Embora o governo militar brasileiro tenha enviado seu representante para emitir a mensagem de que no Brasil a poluição industrial não era um problema, uma nova sensibilidade ambiental já estava em curso. Em outubro de 1973, o governo brasileiro cria a Secretaria Especial do Meio Ambiente (Sema), órgão vinculado ao Ministério do Interior.

Portanto, os livros didáticos de ensino de História Natural, juntamente com os manuais de outras disciplinas escolares, propagam-se num período em que já existe uma sensibilidade ambiental sedimentada na sociedade brasileira. Levando em consideração esse aspecto, a questão que orienta esta pesquisa é: Que concepções de natureza e tipos de sensibilidade ambiental estão presentes nos manuais didáticos de História Natural nesse período (1934-1971)?

O artigo está organizado em três partes. Na primeira, apresentamos uma historiografia que demonstra a existência marcante de um pensamento ecológico e de uma nova sensibilidade ambiental no período histórico abordado. O quadro histórico apresentado desmitifica a visão que ainda impera no senso comum, e na academia universitária de um modo geral, de que no Brasil a crítica ambiental é algo recente. No segundo tópico do artigo, abordamos o papel da História Natural tendo por fundamento a visão dos autores dos livros didáticos observados. Em seguida, apresentamos as concepções de natureza em alguns dos livros selecionados, observando principalmente a organização e o conteúdo referente ao mundo animal e vegetal.

\section{Concepções de natureza e sensibilidade ambiental no contexto histórico}

Em O homem e o mundo natural, Keith Thomas (2001) procura demonstrar que o tema central do seu livro merece um tratamento histórico mais sério. A tese do autor é de que, entre os séculos 16 e 18, na Inglaterra, ocorreu uma profunda transformação na "sensibilidade" da cultura humana em relação à percepção sobre o mundo natural, uma mudança de mentalidade que atingiu todas as classes sociais: surgiram novas sensibilidades em relação a animais selvagens e domésticos, plantas, paisagens e ambientes naturais. As tradicionais práticas de violência contra animais foram sendo questionadas e contestadas; a forma de exploração dos recursos naturais foi acumulando críticas até se materializar em medidas legislativas de proteção ambiental. Mesmo que essa mudança não tenha sido suficiente para conter o ímpeto destrutivo da Revolução Industrial e do capitalismo europeu, Keith Thomas não 
deixa dúvidas quanto ao surgimento de novas concepções de natureza e sensibilidades na história moderna da Inglaterra.

No Brasil, José Augusto Pádua (2004) revela uma história ambiental obscurecida pela historiografia brasileira. Pádua mostra o vínculo entre escravidão e crítica ambiental contido no pensamento político que se forjou no período da pré-independência e no Brasil monárquico. Ele analisou uma expressiva produção intelectual que difundiu críticas e utopias em relação ao "problema da agricultura e da escravidão" e que, ao mesmo tempo, formulou uma crítica ambiental que denunciava a devastação e destruição do patrimônio natural do País. O autor evidencia a crítica ambiental não somente em autores conhecidos da historiografia brasileira, como José Bonifácio e Joaquim Nabuco, mas também em dezenas de outros intelectuais que foram esquecidos ou menosprezados pela história do pensamento social brasileiro.

Atitudes e ideias de proteção à natureza, portanto, estão presentes na história do pensamento brasileiro desde o século 18. No século 19, no período do Império e da Primeira República, formou-se uma tradição intelectual que pensou um modelo de desenvolvimento "ecologicamente" sustentável. Na contracorrente do processo modernizador impulsionado pelo ímpeto capitalista que devasta impiedosamente ecossistemas inteiros, florestas e bacias hidrográficas, surgiu e se desenvolveu uma nova sensibilidade ambiental também em solo brasileiro (Pádua, 2004).

Entretanto, o século em que Charles Darwin escandaliza o mundo ocidental com a publicação de A origem das espécies também é o século das ideologias propagadas pela Revolução Industrial e pelo capitalismo neocolonialista. Nesse período, o Brasil é visto e representado por olhares instrumentados e informados. Motivados pela teoria evolucionista e pela ideologia do progresso, e instrumentalizados pelo modelo de análise da ciência biológica, cedo se percebe a grandeza da natureza brasílica e o desconhecimento sobre ela. Com ajuda dos estrangeiros, sobretudo os cientistas da natureza, o Estado brasileiro é acionado para conhecer suas "riquezas naturais" e construir a Nação (Naxara, 2004).

$\mathrm{Na}$ primeira metade do século 20, as novas elites brasileiras mostram-se ainda seduzidas pelas ideologias de civilização, modernização e progresso. Em contrapartida, dentro do contexto do espírito que anima a Semana de Arte Moderna, um conjunto de intelectuais e cientistas brasileiros projeta a utopia de um modelo de desenvolvimento compatível com a proteção à natureza. José Franco e José Drummond (2009, p. 11) descobriram que esse grupo de intelectuais defendeu "a conservação dos recursos naturais no interesse das gerações futuras e a preservação da diversidade florística e faunística do país, no âmbito de um amplo projeto de reforma da sociedade brasileira". Tratava-se de um grupo bem articulado com cientistas e instituições estrangeiras, e conhecedores da política de proteção à natureza que estava se desenvolvendo nos Estados Unidos e Europa. Além de analisarem as principais obras dos cientistas selecionados - Alberto José Sampaio, Armando Magalhães Corrêa, Cândido de Mello Leitão e Frederico Carlos Hoehne -, Franco e Drummond (2009, 
p. 11-12) investigaram o programa da primeira Conferência Brasileira de Proteção à Natureza, realizada no Rio de Janeiro em 1934.

Uma política de "educação ambiental" é esboçada pelos idealizadores do Programa de Proteção à Natureza. Diante da voracidade insaciável do pensamento desenvolvimentista que assume o controle do Estado a partir de 1930, os protetores da natureza percebem a educação e a instituição escolar como instrumentos estratégicos de educação ambiental das futuras gerações. Em comparação com os dias atuais, em que o Brasil vive a euforia do Programa de Aceleração do Crescimento (PAC) leia-se crescimento econômico -, havia, na década de 1930, "uma visão largamente disseminada na sociedade de que o crescimento econômico deveria ser perseguido a todo custo, incluindo-se, não exclusivamente, os custos ambientais" (Franco; Drummond, 2009, p. 13). Se hoje a aprovação do novo Código Florestal Brasileiro tem gerado frustração e indignação por parte daqueles que almejam um país mais verde e ambientalmente mais ecológico, na época, "o sentimento de frustração diante da insuficiência das medidas adotadas gerou mágoa e ressentimento entre os integrantes do grupo estudado, bem como a impressão de que os imperativos da ciência não estavam sendo ouvidos" (p. 13).

Alberto José Sampaio (apud Franco; Drummond, 2009) idealiza uma nova ciência e propõe programas que ensinem o homem a se integrar ao mundo natural, amá-lo e respeitá-lo. Não se contenta apenas com a criação de uma legislação de proteção à natureza, defende a criação de medidas de fiscalização e punição rigorosa aos infratores e a realização de campanhas educacionais para estimular nas crianças sentimentos de amor e proteção à fauna e flora brasileira e propõe um conjunto de atividades educativas que, comparadas com as políticas atuais, pode ser considerado como a primeira versão de um programa de educação ambiental para o Brasil. Além disso, em suas publicações e relatórios, Sampaio valoriza as iniciativas inovadoras de educadores e autoridades da época. Destaca a experiência de escolas que promoviam novas práticas agrícolas, organizavam clubes agrícolas, atividades práticas de manejo da terra e reflorestamento, organização de clubes e cursos de proteção à natureza, etc. (Franco; Drummond, 2009, p. 45, 100).

Os livros de Eurico Santos também circularam pelas escolas brasileiras de forma direta ou indiretamente pelas apropriações dos manuais didáticos. Santos dedicou sua vida à defesa da natureza e popularização do conhecimento da História Natural do Brasil. Com apoio da Editora F. Briguiet, publicou dezenas de livros no período de 1930 a 1960, entre os quais Da ema ao beija-flor (1938), Pássaros do Brasil (1940), Proteção à fauna indígena (1948), Peixes do Brasil (1952) e Peixes da água doce (1954). ${ }^{1}$ Suas obras evidenciam que Eurico Santos era um metódico estudioso de obras científicas, da cultura popular e que mantinha proximidade com diversas instituições e associações científicas de sua época.

Uma crítica ambiental está presente nas obras de Capistrano de Abreu, Euclides da Cunha, Sérgio Buarque de Holanda, Caio Prado Junior
${ }^{1}$ Na década de 1980, a editora Itatiaia reeditou a coleção Zoologia Brasílica, de Eurico Santos, composta por 11 volumes. 
e Gilberto Freyre. Freyre foi ainda mais profundo, pois publicou em 1937 um ensaio ecológico sobre a história da "civilização do açúcar". Em Nordeste, Freyre (2004) assume a perspectiva ecológica e diz tratar-se de uma análise do Nordeste agrário, aquele que em tempos passados foi "o centro da civilização brasileira"; focaliza "o homem colonizador, em suas relações com a terra, com o nativo, com as águas, com as plantas, com os animais da região ou importados da Europa ou da África" (Freyre, 2004, p. 37). Na década seguinte (1948), o público leitor de São Paulo foi presenteado com a primeira edição do livro História do Rio Tietê, de Mello Nóbrega (1981). O roteiro histórico é constituído pela relação entre o homem paulista e o rio, este ganha status de um personagem histórico de valor inestimável. Nóbrega compõe sua linguagem textual com poesia e escrita documentada e mostra-se familiarizado com os princípios básicos da ecologia e geografia de sua época. O rio, diz o autor, "é o pai dos homens e das árvores, dos animais e das plantas" (Nóbrega, 1981, p. 36). As ideologias do progresso e da civilização limitam o pensamento do autor, mas após a leitura do livro fica difícil pensar a história de São Paulo sem a sua relação com o rio Tietê.

Foi nesse contexto de surgimento de uma vontade de proteção à natureza e proliferação do pensamento ecológico que muitos livros didáticos, entre os quais os de História Natural, foram editados no Brasil. Vejamos, então, algumas das concepções e representações de natureza registradas nos livros de História Natural.

\section{Objetivos do ensino de História Natural segundo os manuais didáticos}

\begin{abstract}
Mas o tear mecânico e a bomba a vapor são, afinal, nada mais do que engenhocas cobertas de valor acidental; e o conhecimento natural enseja miríades de criações mais sutis que não são louvadas por não serem diretamente conversíveis em instrumentos para a criação de riqueza. Quando vejo o conhecimento natural distribuindo tais benesses entre os homens, a única comparação apropriada que posso encontrar para ele é o de uma camponesa dos Alpes, sempre caminhando com dificuldade para cima, pesadamente carregada e com a mente voltada exclusivamente para sua casa; e ainda, sem esforço ou atenção, tricotando para sua prole. Ora, meias são coisas boas e confortáveis e as crianças indubitavelmente muito se beneficiarão com elas; mas, evidentemente, seria obtuso, para dizer o mínimo, depreciar essa mãe laboriosa equiparando-a à mera máquina de fazer meias - uma mera provedora de confortos físicos? (Huxley, 2009, p. 41-42).
\end{abstract}

Na Grã-Bretanha do século 19, Thomas Henry Huxley (1825-1895), naturalista e cientista, foi um importante defensor da teoria da evolução de Charles Darwin e um entusiasta convicto sobre a importância do conhecimento natural na vida das pessoas. Em suas publicações e conferências, defendia de forma enfática o papel das ciências na prática do ensino escolar e acreditava que o "aperfeiçoamento do conhecimento natural" poderia contribuir para o aprimoramento moral do homem e das 
condições de vida da população. Ele compara as descobertas da astronomia com as dos naturalistas. Enquanto os astrônomos descobriram que a Terra não era o centro do universo, "mas um grão de poeira secundário", os cientistas do mundo natural "concluíram que o homem não é o centro do mundo vivente, mas uma entre outras miríades de outras variantes de vida" (Huxley, 2009, p. 52).

No século 20, o ensino de História Natural torna-se uma realidade não somente na Grã-Bretanha como também na América e, particularmente, no Brasil. Com a criação e expansão das escolas públicas, surge a necessidade de produção e comercialização de livros escolares. Mas qual é o papel do ensino de História Natural tal como se apresenta nos manuais didáticos? Em História Natural ou O Brasil e suas riquezas, Waldemiro Potsch (1934) concebe a História Natural como importante instrumento de conhecimento para potencializar a exploração das riquezas naturais. Segundo Potsch (1934, p. 5),

a História Natural estuda os animais que se encontram na superfície do solo ou nas entranhas da terra, ou nos mares e rios. Trata de todas as plantas de nossos jardins e de nossos campos, de todas as árvores das matas, dá nome a cada uma delas, faz conhecer suas propriedades, os seus efeitos, os seus empregos. Estuda ainda os corpos brutos que não têm vida, como as pedras, o manganês, o ouro, etc. Trata de todos os corpos que entram na composição da terra, e da origem e formação da própria Terra.

No caso do Brasil, a História Natural era ainda mais importante porque o País é dono de um território "abençoado por Deus" em termos de riquezas naturais. Waldemiro Potsch $(1934$, p. 6) ressalta que "estudar a história natural é aprender a conhecer as nossas riquezas, a pujança da nossa terra, a terra da Promissão", pois aprender o conhecimento da história natural do País significa demonstrar orgulho patriótico e desenvolver uma educação cívica, "encontrando a cada passo os mais gratos motivos para bendizer a Deus pela grande ventura de sermos filhos da incomparável terra brasileira".

No seu livro didático, Paulo Décourt ([s.d.]) também explicita sua visão sobre o conceito, os objetivos e as subdivisões da História Natural. Identifica-a como uma ciência que tem por objetivo o estudo da natureza. Sendo a natureza constituída por animais, vegetais e corpos brutos, é do âmbito dos "corpos naturais e dos fenômenos que neles se passam" o objeto de estudo da História Natural e explica que os "corpos naturais" são popularmente divididos em três reinos: "animais, vegetais e minerais ou pedras" (Décourt, [s.d.], p. 5). Mas, diferentemente dos animais e vegetais, os minerais não possuem vida, por isso os "corpos naturais" podem ser divididos em dois grupos: vivos e brutos; e os vivos, em dois subgrupos: animais e vegetais. Décourt informa ainda que a História Natural pode ser dividida em duas outras ciências: Biologia e Mineralogia; e, como o homem também precisa conhecer a História Natural do planeta Terra, o estudo da Terra é objeto de outra ciência, a Geologia. A Biologia, por sua vez, ainda é subdividida em mais duas ciências, a Zoologia e a Botânica; 
${ }^{2}$ Tudo indica que a edição em análise ([s.d.]) foi publicada na década de 1960, com o título de Didática de História Natural, pois há uma $2^{\mathrm{a}}$ edição com o mesmo título publicada em 1972. e, por último, Décourt ([s.d.], p. 6) ainda esclarece que cada uma dessas ciências possui suas subdivisões internas.

No final da década de 1950, Oswaldo Domiense de Freitas [s.d.] formulou e publicou uma proposta de Didática de História Natural no curso secundário. A publicação resultou da premiação em primeiro lugar no II Concurso "Dia do Professor", realizado em outubro de 1957 pela Diretoria do Ensino Secundário do Ministério de Educação e Cultura (MEC). ${ }^{2}$ A didática proposta por esse autor evidencia seu otimismo em relação ao poder revolucionário da ciência moderna e do método científico. No capítulo referente aos objetivos, ressalta o "valor pedagógico da História Natural", especificando quatro indicadores: valor informativo, valor educativo ou formativo, valor cultural e valor prático (Freitas, [s.d.], p. 1718). O primeiro aspecto trata dos conhecimentos sobre o mundo natural proporcionados pela disciplina de História Natural. No aspecto formativo, Oswaldo de Freitas propõe a superação do "ensino livresco e verbalista" pelo ensino racional, ou seja, por um ensino baseado nos princípios do método científico. O valor cultural é proporcionado pela "observação da natureza" e pela "inspiração que ela transmite", desenvolvendo "nos adolescentes ideais e sentimentos que orientam sua vida, tornando-a mais valiosa para si e para a sociedade". Quanto ao último aspecto, Freitas argumenta que o ensino de História Natural deve propiciar conhecimento para objetivos úteis e práticos. Entretanto, o fim dessa disciplina não deve se subordinar a meras questões de ordem prática, pois "seria condenável - e contrário à própria finalidade do ensino secundário - sobrepor-se o valor utilitário dos conhecimentos aos objetivos de natureza educativa e cultural" (p. 17-18).

O programa oficial de História Natural, em vigor na década de 1950, indica que as autoridades educacionais já projetavam uma mudança substancial na concepção e objetivos da disciplina. Oficialmente, o ensino de História Natural já estava sendo orientado para se metamorfosear em ensino de Biologia Moderna. O programa oficial proposto pela Portaria Ministerial no 966, de 2 de outubro de 1951, para a $3^{a}$ série do curso clássico, evidencia as mudanças que já estavam em curso.

De acordo com a portaria apresentada por Oswaldo Domiense de Freitas em seu livro, o ensino de História Natural deveria dar conta de dez unidades, e mais da metade delas abrange conteúdos que hoje estão presentes nos livros didáticos de Biologia: introdução ao estudo da História Natural; a vida; organização dos seres vivos; as funções orgânicas; classificação dos seres vivos; relações entre os seres vivos. No âmbito de cada unidade, recomenda-se que os professores trabalhem com o conceito de vida, célula, tecidos, órgãos, hereditariedade, etc. Sobre a classificação dos seres vivos, propõe-se o ensino da tradicional classificação utilitarista: vegetais úteis e nocivos, animas úteis e nocivos (Freitas, [s.d.]).

Na prática, o fim da disciplina de História Natural representa uma suposta "evolução" de uma disciplina que se propunha a estudar o mundo natural na sua totalidade. À medida que a sociedade brasileira entra no fluxo do progresso da modernidade, a ideia de conhecimento 
geral perde prestígio para o conhecimento científico fragmentado, que se apresenta na forma de novas especialidades científicas que prometem um conhecimento mais profundo sobre os elementos constitutivos da natureza. Assim, a disciplina de História Natural perde o seu estatuto de disciplina ao mesmo tempo que dá à luz novas especialidades, as quais já estavam sendo gestadas dentro do seu próprio campo de atuação. Mais do que um suposto processo "natural" de mudança, as novas especialidades conquistam prestígio e estatuto de "novas ciências" à medida que provam serem mais úteis e mais eficientes para o desenvolvimento econômico moderno e capitalista da sociedade brasileira.

\section{Os animais e as plantas no ensino de História Natural}

Na contracapa do livro Primeiro ano de História Natural, do engenheiro militar Miguel Tenório D’Albuquerque, publicado em 1933, consta a divulgação de dezenas de livros escolares da Editora e Livraria Jacintho, onde esse autor publicou outras oito obras: Compêndio de Física; Apontamento de Química Geral; Alguns problemas de Química; Fórmulas de Geometria; Ciências Físicas e Naturais ( $1^{\mathrm{a}}$ e $2^{\mathrm{a}}$ séries); Primeiro ano de Física e Química (3ª série); Álgebra; Apontamentos da língua tupi-guarani. $\mathrm{Na}$ folha de rosto do livro, informa-se que a obra estava de "acordo com o programa do Colégio Pedro II e Instituto de Educação".

O Primeiro ano de História Natural está dividido em quatro partes: Botânica, Zoologia, Mineralogia e Geologia. O conteúdo é apresentado na forma de estudos descritivos e comparativos, acompanhado de figuras ilustrativas. No capítulo sobre a Botânica, trata de plantas e árvores com flores, práticas de germinação e enxertos, estudos descritivos de samambaias, de musgo e líquen. Insere a ecologia para descrever a relação dos vegetais com o meio ambiente, especificamente para falar da influência da luz, do ar, da água e do solo no desenvolvimento das plantas. Mostra divisões gerais do reino vegetal e destaca a "utilização dos vegetais e dos seus produtos" para os seres humanos.

A lição de ecologia revela uma das interpretações reducionistas da teoria evolucionista de Darwin. Sobre as relações entre os animais e o meio ambiente, o manual didático ensina que "um animal, qualquer que ele seja, qualquer que possa ser sua colocação na escala zoológica, tem sempre que lutar contra o meio que o cerca, para não ser vencido, para poder viver e reproduzir-se" (D'Albuquerque, 1933, p. 188). O livro ensina que luta e competição são leis da natureza e que a vida é uma constante "luta contra o meio, e do meio contra o sêr [sic]", entretanto, "nessa luta entre o sêr e o meio que o cerca, devem existir relações harmônicas", e o animal deve "adaptar-se ao meio, procurando modificá-lo segundo suas próprias necessidades" (p. 188).

Dentre os animais com maior capacidade de luta e adaptação, o autor destaca as qualidades superiores do homem, o qual "não só procura adaptar-se, como ainda procura melhorar os elementos que produzirão 
3 Os livros identificados como "compêndios" possuem uma configuração mais racionalista. Apresentam conceitos e descrições empregando uma linguagem mais científica, primando por uma objetividade racional desprovida de reflexão crítica e/ou expressões que indicam sentimentos e valores morais. Mesmo assim, percebese claramente a concepção de natureza dos livros. São "aqueles livros que se caracterizam como uma exposição didática de um conjunto de conteúdos, organizados de forma progressiva, tendo em vista áreas de conteúdo diferentes" (Batista; Galvão; Klinke, 2002, p. 37). a alimentação" para a sua reprodução e prazer; e, por ser dotado de inteligência, "o homem tenta sempre tornar bom, aceitável, um meio prejudicial, e regiões completamente estéreis e inóspitas ou insalubres são completamente transformadas para o uso do conjunto" (D'Albuquerque, 1933, p. 190-192). Praticamente todos os tipos de animais, assinala o autor, são úteis ao homem, de forma direta ou indireta. Na dieta alimentar, os mais consumidos são gado, galinhas, perus e peixes, "mas há pessoas que comem caças e passam dias e noites nas matas e florestas, matando cotias, pacas, tatus e várias aves" (p. 191); e há aqueles que também têm uma dieta alimentar constituída regularmente por ofídios, rãs e quelônios. Além da alimentação, os animais também se prestam a satisfazer diversas outras necessidades humanas. Entre os animais que contribuem para o progresso social, o autor lembra os cavalos, cães, elefantes e renas. Do gado, o homem aproveita o couro e do elefante aproveita o marfim; do tigre, do leão e de diversos outros animas, o homem aproveita a pele para fins ornamentais, "inclusive os pobres passarinhos inofensivos"; no mar, o homem caça a baleia, o cachalote, o tubarão e o tintureiro para produzir azeite (p. 190-192).

Os livros didáticos de História Natural de Carlos Costa (1939) e Paulo Décourt ([s.d.]) possuem a forma de compêndios e apresentam uma configuração muito semelhante. ${ }^{3}$ Na década de 1930, a Companhia Editora Nacional publicou três volumes do livro de História Natural do Dr. Carlos Costa - um volume para o $3^{\circ}$ ano ginasial, um segundo para o $4^{\circ}$ e um terceiro volume para o $5^{\circ}$ ano ginasial. Considerando o públicoalvo ao qual é destinado, ou seja, crianças e adolescentes do ensino ginasial, a linguagem textual do livro didático de Costa é muito científica e complexa. Diferentemente de outras obras didáticas, os temas abordados em Botânica, Zoologia, Mineralogia e Geologia são descritos com uma linguagem científica dificilmente compreensível para as crianças escolares. A seção de Botânica, por exemplo, apresenta os elementos constitutivos dos vegetais (flores e plantas) com descrições sobre as características e funções das partes das plantas acompanhadas de ilustrações, fazendo uso de termos pedagogicamente inadequados para a idade das crianças. Observando apenas a divisão do capítulo sobre a origem e constituição da flor, pode-se perceber a racionalidade predominante da linguagem da obra: "Simetria floral; fórmulas e diagramas florais, Prefloração; Inflorescências, seus tipos; Estudo especial do perianto, do androceu e do gineceu" (Costa, 1939 , p. 11). Essa linguagem técnica e a concepção de natureza que está implícita e explícita nas imagens e descrições conceituais são praticamente as mesmas dos livros didáticos de ensino de Biologia Moderna.

No período de 1930 a 1960, o livro Noções de História Natural, de Paulo Décourt, foi reeditado frequentemente. A edição para o $3^{\circ}$ ano do curso ginasial está dividida em quatro partes e 15 capítulos: Botânica, Zoologia, Mineralogia e Geologia. A organização e a descrição do conteúdo evidenciam que o livro já possui as características semelhantes aos compêndios de Biologia. Em uma rápida visão geral sobre o sumário, percebe-se que o compêndio de Décourt, tal como a maioria dos 
compêndios da época, transpõe para a escola o conhecimento científico em linguagem científica. As espécies do mundo natural são divididas em partes, que ganham visibilidade e valorização em detrimento do todo, que perde sua identidade popular.

- Da História Natural, sua definição, divisão e subdivisões.

- Reinos da natureza. Diferenças entre seres brutos e vivos e entre animais e vegetais; Diferença entre seres brutos e vivos; Diferença entre animais e vegetais [...].

- Constituição do organismo vegetal. Divisões gerais do reino vegetal.

- Estudo descritivo e comparativo de plantas providas de flores, herbáceas e lenhosas, arborescentes, sarmentosas e rastejantes; caracteres gerais: raiz, caule, folha, flor, fruto, semente. Estudo experimental da germinação. Enxertos [...].

- Estudo descritivo e comparativo de exemplos de samambaias, caracteres gerais, raiz, caule, folha, esporângio, esporo, protalo. Ciclo reprodutivo.

- Estudo descritivo de um musgo; caracteres gerais; rizóide, talo, folha, esporângio, esporo, protonema. Ciclo reprodutivo [...]

- Estudo descritivo de um Líquen; caracteres gerais: talo, esporo. Simbiose; Relações entre o vegetal e o meio; Influencia da luz, do ar, da água e do solo; Tropismos; Geotropismo; Fototropismo [...]; Utilização dos vegetais e dos seus produtos.

- O homem: raças e seus caracteres; membros superiores e inferiores; Órgãos dos sentidos [...]; Cérebro; Sistema nervoso; Órgãos internos; Aparelho digestivo [...].

- Estudo descritivo e comparativo de animais domésticos: aves, lagartos, sapos e peixes; caracteres ferais: membros, esqueletos. Caracteres da dentição dos animais domésticos.

- Estudo descritivo de um caramujo, de um verme, de uma estrela do mar; caracteres gerais, divisões do corpo; simetria lateral e radiada [...]; Utilidade dos animais e dos seus produtos; Divisões gerais do reino animal [...]. (Décourt, [s.d.], Sumário).

O livro de Paulo Décourt concebe a natureza na perspectiva antropocêntrica da ciência moderna. As características das espécies do mundo natural são descritas por meio de linguagem técnica (objetividade científica) que evita juízo de valor e expressões que exaltam a exploração econômica da natureza, como faz a pedagogia liberal. A concepção do livro, no entanto, reproduz a tradicional visão moderna que separa o homem da natureza. O homem é explicitamente considerado a espécie superior do reino animal, pois "ele distingue-se dos outros animais por ser o único em que se observa a moralidade e a religiosidade"; e "por essas razões já se quis formar com o homem um terceiro reino vivo, o reino humano" (Décourt, [s.d.], p. 131).

A linguagem do livro revela um conhecimento científico que penetra nas entranhas do mundo natural, esmiúça suas partes visíveis e invisíveis, inventa conceitos e terminologias científicas, descreve as funcionalidades dos "corpos naturais" tal como um professor de Medicina em uma aula de Anatomia Humana (com um cadáver como modelo) ou um biólogo que ensina o conceito de vida por meio de uma espécie do mundo natural, que é sacrificada para ensinar aos estudantes os segredos da natureza. 
Waldemiro Potsch era professor do Colégio Pedro II e produziu uma expressiva bibliografia na área de Ciências Físicas e Naturais. A primeira edição de História Natural ou O Brasil e suas riquezas é de 1921. A $11^{\text {a }}$ edição (1934) ganhou uma "feição material profundamente modificada" e melhorada, segundo o autor. Nas páginas iniciais da $11^{\mathrm{a}}$ edição, informa-se o leitor de que o livro de Waldemiro Potsch foi classificado em $1^{\circ}$ lugar no concurso realizado pela Academia Brasileira de Letras sobre obras de divulgação do ensino primário; apresenta-se, inclusive, o parecer da comissão que avaliou o mérito da obra em 24 de novembro de 1922: "a obra é excelente no método, clara na exposição, extreme na linguagem, fácil sem ser trivial". Além disso, também consta uma apresentação elogiosa de Carlos Chagas, que afirma que "a educação em assuntos gerais de biologia, e especialmente de higiene, encontra sua melhor oportunidade nas escolas, onde devemos bem aproveitar a inteligência infantil (...)"; e "com método e acerto o autor sintetizou as noções elementares essenciais de história natural e imprimiu no trabalho um cunho de nacionalismo pelo zelo dispensado às cousas da nossa terra" (Potsch, 1934, Prefácio).

O livro O Brasil e suas riquezas expressa a clássica visão ufanista das elites brasileiras que idealizaram o País como "Celeiro do Mundo". Para vislumbrar um futuro promissor, Potsch exalta as potencialidades naturais de um Brasil deitado em berço esplêndido. No início da obra, apresenta-se um ranking mundial da produção agropecuária e produção mineral, onde se situa a classificação do País no cenário internacional: $1^{\circ}$ lugar na produção de café, $1^{\circ}$ lugar em minério de ferro, $2^{\circ}$ lugar na produção de borracha, $3^{\circ}$ lugar na produção de arroz, $4^{\circ}$ lugar na criação de bovinos, etc. Entre os animais domesticados, Potsch (1934, p. 1826) expressa visível admiração pelos bovinos. Dedica dez páginas para ressaltar e valorizar a importância da criação de bovinos para a economia nacional e lembra que na mitologia egípcia antiga o boi tinha status de um "glorioso Deus". O livro didático de Waldemiro Potsch contém descrições baseadas em princípios ecológicos, mas a motivação é predominantemente de ordem econômica.

Balduíno Rambo (1905-1961) foi um padre jesuíta que se dedicou à missão educativa. Ele nasceu na microrregião de Montenegro, no distrito de Tupandi, no Rio Grande do Sul (RS) em 1905 e lecionou no Colégio Anchieta de Porto Alegre no período de 1939 a 1961, ano em que faleceu. Foi professor da disciplina de Antropologia e Etnografia na Universidade Federal do Rio Grande do Sul (UFRGS) e também lecionou no Colégio Catarinense e na Faculdade Cristo Rei, em São Leopoldo (RS). Organizou uma das maiores coleções de plantas da Região Sul - cerca de 120.000 espécies -, coleção institucionalizada no Herbário Anchieta, que atualmente pertence à Universidade do Vale do Rio dos Sinos (Unisinos). Além desse importante trabalho, também foi diretor do Museu de Ciências Naturais do Rio Grande do Sul, na época em que propôs a criação do Horto Florestal do Parque Zoológico do Estado. Era um admirador e frequentador do Canyon Itaimbezinho, lugar onde se sentia mais conectado com a beleza do mundo natural. Foi ele que iniciou a demarcação para o futuro 
Parque Nacional de Aparados da Serra, na fronteira entre Rio Grande do Sul e Santa Catarina (Sander, 2005). Na memória do Rio Grande do Sul, é reconhecido como "apóstolo dos humildes", educador, escritor, cientista e poeta. Durante sua vida de professor e pesquisador, publicou cerca de 100 livros. A maioria de suas publicações concentra-se em História Natural, Geografia e Botânica.

No âmbito do ensino escolar, publicou, em 1934, Elementos de História Natural, livro reeditado em 1935, 1936, 1937 e 1939. Ainda em 1934, publicou Elementos de Química para o $3^{\circ}$ ano seriado e para o $4^{\circ}$ ano seriado, também pela Livraria do Globo, de Porto Alegre.

No prefácio de Elementos de História Natural, padre Rambo diz: "O fim dêste volume é de satisfazer as exigências do programa oficial ora vigente [...]; na $3^{\mathrm{a}}$ série, o ensino visa não só ao conhecimento geral das espécies e dos seus órgãos e funções mais importantes, como a reunir, objetivamente, os subsídios necessários à sistemática das principais formas da flora e fauna regionais" (Rambo, 1934, p. 5). Salienta que se esforçou para evitar o uso de uma linguagem técnica e de termos estrangeiros.

Esse livro didático foi organizado com textos descritivos e figuras em preto e branco, e, como assinala no prefácio, procura descrever cada espécie do mundo natural em "linguagem acessível". Descreve as características de cada espécie usando o nome popular no texto e o nome científico entre parênteses. Diferentemente dos autores que primam por uma linguagem científica desprovida de sentimentos e juízo de valor moral, a forma e o conteúdo da linguagem de seu livro evidenciam uma sensibilidade ambiental preservacionista. A linguagem escrita transmite certo equilíbrio entre razão e sensibilidade, conhecimento científico e conhecimento popular, informação e admiração, objetividade e crítica ambiental. Explicita claramente sua admiração e preocupação com "florestas virgens" e animais silvestres. A expressão "amigos da natureza" aparece frequentemente nas descrições. Quando descreve as características do bugio (mycetes fuscus), espécie de macaco comum na Mata Atlântica do Rio Grande do Sul e Santa Catarina, por exemplo, descreve da seguinte forma:

\footnotetext{
Nenhum amigo de nossas florestas virgens desconhece este macaco de pêlo ruivo, cabeça maciça, mandíbula inferior alta e ornada de barba, que, inofensivo e retirado, vive na solidão da mata. Reunidos em bandos de três a dez indivíduos de todas as idades e sexos, e guiados por um macho velho e experto, os bugios raras vezes se afastam de seu paradeiro de poucas léguas de circuito, que lhes fornece pasto e proteção. (Rambo, 1934, p. 33).
}

Logo em seguida assinala: "cada movimento do bugio traduz grande segurança e certa dignidade"; com as mãos, "parecidas com a mão humana, segura-se aos galhos, levando o peso do corpo com os músculos vigorosos dos braços"; seus uivos ressoam na mata como "um dos sons naturais mais imponentes das matas sul-americanas" (Rambo, 1934, p. 34-35). 
${ }^{4}$ Diferentemente da linguagem técnico-científica que predomina no seu livro didático, em dois outros livros Cândido de Mello-Leitão revela uma sensibilidade ambiental mais sentimental e política. Em 1935 a Editora Nacional publicou Vida maravilhosa dos animais e em 1940 publicou A vida na selva. Atualmente esses dois livros poderiam ser classificados como paradidáticos
Cândido de Mello-Leitão foi zoólogo e professor do Museu Nacional do Rio de Janeiro, juntamente com Alberto José Sampaio e Armando Magalhães Corrêa. Publicou dezenas de livros na área científica e educacional. Além de se dedicar à causa da proteção à natureza, também foi um entusiasta do desenvolvimento da pesquisa científica (Franco; Drummond, 2007, 2009). A segunda edição do primeiro volume do seu livro Curso elementar de História Natural (1933) está dividida em cinco partes: Botânica, Antropologia, Zoologia, Mineralogia e Geologia - no segundo volume, excluiu a parte referente à Antropologia. O autor é identificado como professor de Zoologia do Museu Nacional e professor de História Natural do Instituto de Educação. O primeiro volume (1933) é dedicado a Roquete Pinto e o segundo (1934), aos "Professores de História Natural dos Institutos Estaduais e Particulares". Além de agradecer aos professores por terem aceitado muito bem o primeiro volume de seu livro didático, Mello-Leitão (1934, Prefácio) informa que o plano geral da obra é constituído por três volumes e que se trata de um "trabalho moderno"; salienta que o livro foi propositadamente escrito em "moldes diversos dos compêndios comuns e fora do sistema", e ao gosto dos "professores improvisados".

O Curso elementar de História Natural, de Mello-Leitão, possui uma configuração muito semelhante à dos livros didáticos de Biologia moderna que começam a se difundir a partir da década de $1960 .{ }^{4}$ As descrições textuais primam por uma linguagem mais técnica, desprovida de expressões sentimentais, valor moral, crenças populares, noções religiosas e sentimentos patrióticos, comuns nos manuais didáticos que não incorporaram a racionalidade científica de matriz positivista. Mas, diferentemente dos positivistas clássicos, no livro didático de MelloLeitão nota-se um conteúdo que articula de forma mais consistente conhecimento científico e princípios ecológicos. As atividades pedagógicas se baseiam nos princípios básicos do método científico. Na primeira parte, o autor apresenta uma introdução procurando ensinar os professores a usar o microscópio como ferramenta didática com os estudantes, com o objetivo de ensinar a observar e conhecer as partes invisíveis das plantas e dos micro-organismos. Todos os capítulos contêm ilustrações e textos temáticos descritivos e orientações didáticas ao professor, como a organização de uma aula para ensinar os estudantes a observarem cientificamente uma folha:

Ao Professor. Ainda aqui seguir o que aconselhamos nas páginas 15 e 17 do primeiro volume. Dar a cada aluno algumas fôlhas [sic] com um questionário. Vamos supor, por exemplo, entre outras a fôlha do maracujá do mato, sendo o questionário a responder o seguinte: Essa fôlha é simples ou composta? É completa? O que lhe falta? Tem órgãos acessórios? Quais? Pouco ou bem desenvolvidos? Qual a forma do limbo? Qual a nervação? É inteira? Tem pêlos ou acúleos? A gavinha que aí está é caule ou fôlha? É uma fôlha de mono - ou de dicotilédone? Como é o epiderna? (Mello-Leitão, 1934, p. 104).

Mello-Leitão preocupa-se em oferecer um manual didático acessível aos professores do ensino secundário. Mais do que acessível, no entanto, é 
sua estratégia de incutir o espírito científico na prática do ensino e difundir a linguagem científica na cultura escolar. A terminologia científica é uma das características marcantes de seu livro didático. Também são visíveis a influência da teoria da evolução de Darwin e alguns princípios básicos da biologia ecológica. No capítulo sobre o crescimento das plantas, fala dos agentes internos e externos que influenciam na evolução ou não dos vegetais. Da mesma forma que nos demais capítulos, Mello-Leitão descreve seu objeto de estudo a começar da parte (célula, embrião, semente, caule) para o todo (organismo, corpo). Na parte sobre o ensino de Zoologia, Mello-Leitão organizou 13 capítulos para explicar conceitos sobre "célula, animais unicelulares, aparelhos e funções de relação no homem e nos animais". Conforme indicam os títulos dos capítulos, sua pedagogia parte sempre do estudo das partes para o todo, mas em muitos aspectos descreve apenas a função das partes que compõem os organismos. O primeiro capítulo começa com a célula animal. Sobre protozoários, por exemplo, sugere:

Ao professor. Para o estudo dos protozoários deve o professor ter lâminas com preparações coloridas de tripanosomas e hematozoários, assim como de ciliados (para demonstração dos núcleos). Para o exame a fresco procurar ter em cubas separadas amebas, flagelados e infusórios. Pesquisar em aulas gregarinas. Fazer uma preparação para pesquisa do hemosporídio do pombo. Eis como proceder: [seguem as orientações]. (Mello-Leitão, 1934, p. 178).

Levando-se em consideração a mentalidade predominante da cultura brasileira no contexto inicial da década de 1930, o manual didático de Mello-Leitão apresenta uma dose de racionalidade científica bem acentuada para a época. No capítulo sobre "Fisiologia do sistema nervoso", trata do reflexo muscular por meio da clássica experiência com uma rã: "Suspendendo-se uma rã decapitada, veremos que as patas não pendem frouxas e relaxadas, mas permanecem em ligeira flexão, isto é, em uma posição intermediária entre a normal e a vertical", e explica que isto ocorre porque "a pele, os tendões e as articulações da pata, estendida pela ação da gravidade, enviam à medula excitações que provocam uma certa flexão tônica da extremidade" (Mello-Leitão, 1934, p. 256). Dessa forma, "se seccionamos as raízes posteriores de um dos lados, desaparece o tono flexor do mesmo lado". Em síntese, propõe uma prática de ensino que propicie aos estudantes conhecer o mundo natural por meio do método científico. $^{5}$

Em se tratando de um manual didático destinado aos professores do ensino secundário, cabe aqui uma indagação pedagógica. Como se explica esse fenômeno em uma sala de aula repleta de adolescentes, sem despertar algum tipo de compaixão para com o "objeto" do ensino? Sem dúvida, a linguagem científica é o modo mais eficiente para essa forma de ensinar, mas, quando se organiza uma experiência científica com animais não humanos, o que se ensina aos estudantes além dos objetivos pedagógicos propostos?
${ }^{5}$ Nos manuais de ensino de História Natural, Ciências e Biologia que se fundamentam no método científico, as experiências didáticas com sapos e rãs seguem um padrão que se percebe ainda hoje em muitos livros didáticos. 
Estudos Sociais e Naturais, organizado por Maria Guimarães Ribeiro, Edith Guimarães Lima e Giselda Guimarães Gomes (1958), é um livro didático destinado às crianças escolares do ensino primário. O conteúdo do livro foi adaptado para a história social e natural do Rio Grande do Sul. A configuração é composta por textos informativos curtos, pequenas histórias, ilustrações em forma de desenho e atividades didáticas para as crianças interagirem com o livro (questões para completar, para assinalar, para se localizar, para observar, entre outras) e também interagirem com o ambiente natural. A linguagem do livro é apropriada para as crianças escolares do ensino primário.

O capítulo referente ao "Programa de Estudos Naturais" está organizado em quatro temas: homem, animais, plantas e fenômenos naturais. Quanto ao homem, no livro apresentam-se informações sobre o corpo humano, suas partes e funções; quanto aos animais e às plantas, apresentam-se as que existem na localidade, informações sobre utilidade e cuidados básicos; quanto aos fenômenos naturais, ensinam-se noções básicas sobre o tempo, o clima, o movimento da Terra, do sol, da lua e das estrelas, os pontos cardeais, as águas e os ventos.

Pedagogicamente, a organização didática do livro fundamenta-se em estratégias que motivam as crianças a conhecerem, a memorizarem, a pesquisarem, a fazerem, a observarem e a sentirem o mundo natural. A narrativa, as ilustrações e os exercícios de aplicação propiciam o desenvolvimento de habilidades cognitivas e sensibilidades sociais e naturais. As atividades didáticas não se restringem ao espaço da sala de aula, mas estimulam atividades práticas e observações diretamente no meio natural. Entretanto, a forma como o mundo natural está representado no manual mostra claramente que se trata de um livro com característica de cartilha de educação antropocêntrica, ou seja, um manual didático de iniciação pedagógica à cultura antropocêntrica. A natureza é tema de conhecimento em função dos interesses e das necessidades da sociedade humana. Ensinam-se noções básicas de História Natural na perspectiva do "homem". A lógica utilitarista da cultura antropocêntrica está relativamente bem caracterizada no conteúdo, nas ilustrações, nos exercícios de aplicação e nos testes de revisão da matéria.

Quando se ensinam as diferenças entre animais domésticos e selvagens, por exemplo, percebe-se que a escola também naturaliza a domesticação do mundo natural para benefício exclusivo do homem. Além disso, percebem-se as características de uma mentalidade que hoje nos parece estranha, principalmente se nos deparássemos com um livro didático que ensinasse as utilidades da domesticação dos elefantes e o valor nutritivo da carne de veado: "Animais selvagens são os que vivem nas florestas, selvas, matos... Alguns deles, como vimos [leão, tigre, onça], são ferozes, nocivos; outros nos podem ser úteis, como o elefante, que serve como meio de transporte, o veado cuja carne comemos" (Ribeiro; Lima; Gomes, 1958, p. 74). Os exercícios de aplicação e os testes de revisão são recursos didáticos eficientes para iniciação e aprimoramento da cultura escolar antropocêntrica. 
O livro Estudos Sociais e Naturais possui linguagem, objetivos e estratégias voltados para o desenvolvimento de sensibilidades ambientais de afeto e cuidado com animais e plantas. Mesmo assim, trata-se do ensino de cuidados visando ao bem-estar de animais e plantas que são úteis aos humanos. O capítulo sobre as plantas apresenta um conjunto de conhecimento sobre as características dos vegetais, suas partes, suas funções, etc. Apresenta uma classificação com base na utilidade da planta para a cultura humana: plantas úteis para a alimentação, plantas medicinais, árvores para extração da madeira.

O livro didático estimula uma educação para a sensibilidade ambiental afetiva. Entretanto, ressalta os valores tradicionais da cultura antropocêntrica moderna, e o programa de estudos da natureza carece dos princípios básicos da ciência ecológica ou do pensamento ecológico da época.

\section{Considerações finais}

De um modo geral, todos os livros escolares observados se acomodam dentro do paradigma da cultura antropocêntrica ou, mais especificamente, dentro da ética "especista" dos animais humanos. Entretanto, há diferentes concepções e sensibilidades ambientais nos livros de ensino de História Natural. São diferenças que expressam a diversidade cultural e a pluralidade de pensamento da sociedade brasileira na época em que as obras foram publicadas.

Alguns livros apresentam características predominantes de uma visão pedagógica antropocêntrica tradicional. Nesses manuais didáticos, a linguagem do livro expressa um pensamento pedagógico que concebe e valoriza a teoria do homem racional e/ou o dogma tradicional da teoria criacionista. A forma e o conteúdo do livro representam a natureza pela sua utilidade econômica e doméstica. As informações e descrições sobre o mundo natural evidenciam equívocos que indicam desconhecimento da biologia ecológica. A linguagem escrita contém expressões que indicam juízo de valor moral, noções religiosas e afirmações desprovidas de fundamento científico.

Uma visão pedagógica científica está presente na maioria dos livros observados. Nessa visão, identificamos três perspectivas: uma visão científica tradicional, uma conservacionista e outra liberal. A visão científica positivista percebe as potencialidades da natureza como recurso natural e projeta a ideia de um Brasil como potência econômica do futuro; fundamenta-se nas ciências da natureza e usa a linguagem científica para descrever os recursos naturais, evitando expressões que indicam juízo de valor moral, crenças populares e noções religiosas. A natureza é compartimentada e descrita por meio de uma linguagem que se reveste de objetividade científica.

Nos manuais que possuem características predominantes de uma pedagogia científica conservacionista, os conteúdos explicitam críticas 
ambientais e preocupação em preservar o mundo natural. São livros que ressaltam a importância dos recursos naturais para o desenvolvimento econômico e tecnológico da civilização humana, razão pela qual a natureza precisa ser preservada e racionalmente explorada. A ciência e o conhecimento científico são valorizados; apresentam-se descrições informativas e conceituais em linguagem científica, mas não se adota a concepção de neutralidade da visão positivista. Na prática do ensino, propõem-se atividades pedagógicas baseadas nos princípios do método científico.

Nos livros didáticos em que predomina uma visão científica liberal, a natureza é enfaticamente reduzida a um conjunto infinito de recursos naturais que deve ser explorado em prol do engrandecimento da pátria e crescimento econômico do País. Com base no método científico, propõe-se uma metodologia de ensino ativa e inovadora, que ensine estudantes e professores a compreenderem e apreenderem o mundo natural e os fenômenos da natureza por meio de observação analítica, pesquisa de campo e experimentações planejadas. Nos manuais didáticos em que predomina essa visão pedagógica, observa-se de forma implícita ou explícita a valorização entusiasmada do progresso científico e do trabalho dos cientistas em prol do crescimento econômico do País. São nesses livros que identificamos alguns dos ideais dos pensadores brasileiros da Escola Nova.

Entre os livros didáticos observados, também identificamos uma visão pedagógica preservacionista. São livros em que se percebe uma visão pedagógica que procura superar a visão utilitarista e economicista da cultura humana em relação ao mundo natural, livros com conteúdo que concebe a ideia de aprimoramento moral do caráter humano por meio do conhecimento ecológico e a ideia de valor estético e espiritual na relação com o mundo natural; conteúdo que expressa críticas contra práticas de degradação ambiental e violência animal e explicita sentimentos em relação a animais domésticos e selvagens. Os livros que possuem essa perspectiva apresentam uma configuração linguística que combina razão científica e sensibilidade ambiental.

A visão pedagógica preservacionista é a que mais se aproxima da pedagogia ecológica do século 21. Atualmente, está se desenvolvendo uma pedagogia ecológica - biocêntrica ou ecocêntrica - que procura transcender o paradigma da cultura antropocêntrica. Essa nova pedagogia expressa críticas ao imperialismo antropocêntrico e defende uma mudança radical no modo como os seres humanos percebem a natureza; estabelece uma comparação crítica entre a prática racista e a especista, visão que concebe o planeta como um ecossistema integrado por todos os seres vivos e cujo equilíbrio ambiental e ecológico depende da diversidade da vida de todos, independentemente dos interesses e desejos dos humanos. Essa visão ressalta a importância da percepção holística, dos ecossistemas, das comunidades bióticas, da biologia ecológica, da ética da vida (cf. Singer, 1998, Felipe, 2007). 


\section{Referências bibliográficas}

BATISTA, Antônio Augusto Gomes; GALVÃO, Ana Maria de Oliveira; KLINKE, Karina. Livros escolares de leitura: uma morfologia (18661956). Revista Brasileira de Educação, Rio de Janeiro, n. 20, p. 27-47, maio/ago. 2002.

BIBLIOTECA do livro didático. Universidade de São Paulo. [s.d.].

Disponível em: < http://www4.fe.usp.br/biblioteca/acervos/bibliotecado-livro-didatico >. Acesso em: 19 set. 2013.

BITTENCOURT, Circe. Disciplinas escolares: história e pesquisa. In: OLIVEIRA; RANZI (Org.). História das disciplinas escolares no Brasil: contribuições para o debate. Bragança Paulista: Edusf, 2003.

BITTENCOURT, Circe. Livro didático e saber escolar (1810-1910). Belo Horizonte: Autêntica, 2008. (História da Educação).

BRASIL. Ministério da Educação (MEC). Sistema educativo nacional de Brasil. Madrid: Organización de Estados Iberoamericanos, 2002. Disponível em: http://www.oei.es/quipu/brasil/index.html\#sis. Acesso em: mar. 2012.

CHOPPIN, Alain. História dos livros e das edições didáticas: sobre o estado da arte. Revista Educação e Pesquisa, São Paulo, v. 30, n. 3, p. 549-566, 2004.

COSTA, Carlos. História Natural: para a quinta série ginasial. 2. ed. São Paulo: Companhia Editora Nacional/ Biblioteca Pedagógica Brasileira, 1939. (Série II, Livros Didáticos).

D'AlBUQUERQUE, Miguel Tenório. Primeiro ano de História Natural. 1. ed. Rio de Janeiro: Ed. Livraria Jacintho, 1933.

DÉCOURT, Paulo L. Noções de História Natural. São Paulo:

Melhoramentos, [s.d.].

FELIPE, Sônia T. Ética e experimentação animal: fundamentos abolicionistas. Florianópolis: Ed. da UFSC, 2007.

FRANCO, José Luiz de Andrade; DRUMMOND, José Augusto. Cândido de Mello Leitão: as ciências biológicas e a valorização da natureza e da diversidade da vida. História, Ciências, Saúde Manguinhos, Rio de Janeiro, v. 14, n. 4, p. 1265-1290, out./dez. 2007.

FRANCO, José Luiz de Andrade; DRUMMOND, José Augusto. Proteção à natureza e identidade nacional no Brasil: anos 1920-1940. Rio de Janeiro: Ed. Fiocruz, 2009. 
FREITAS, Oswaldo Domiense de. Didática de História Natural. Rio de Janeiro: MEC, [s.d.].

FREYRE, Gilberto. Nordeste: aspectos da influência da cana sobre a vida e a paisagem do Nordeste do Brasil. 7. ed. rev. São Paulo: Global, 2004.

HUXLEY, Thomas Henry. Escritos sobre ciência e religião. São Paulo: Unesp, 2009.

MELLO-LEITÃO, C. de. Curso elementar de Historia Natural. 2. ed. São Paulo: Companhia Editora Nacional, 1933. v. 1 (Biblioteca Pedagógica Brasileira, Série II, Livros Didáticos).

MELLO-LEITÃO, C. de. Curso elementar de Historia Natural. São Paulo: Companhia Editora Nacional, 1934. v. 2. (Biblioteca Pedagógica Brasileira, Série II, Livros Didáticos).

NAXARA, Márcia Regina Capelari. Cientificismo e sensibilidade romântica: em busca de um sentido explicativo para o Brasil no século XIX. Brasília: Editora UnB, 2004.

NOBREGA, Mello. História do Rio Tietê. 3. ed. revista. Belo Horizonte: Itatiaia, 1981.

PÁDUA, José Augusto. Um sopro de destruição: pensamento político e crítica ambiental no Brasil escravista, 1786/1888. 2. ed. Rio de Janeiro: Jorge Zahar, 2004.

POTSCH, Waldemiro. História Natural ou O Brasil e suas riquezas. 11. ed. Rio de Janeiro: Oficinas Gráficas Villas Boas , 1934.

RAMBO, Balduíno. Elementos de História Natural para o $3^{\circ}$ ano seriado. Porto Alegre: Livraria do Globo, 1934.

RIBEIRO, Maria Guimarães; LIMA, Edith Guimarães; GOMES, Giselda Guimarães. Estudos Sociais e Naturais: segundo ano. 14. ed. São Paulo: Ed. do Brasil, 1958.

SANDER, Martin. Centenário de nascimento do pe. Balduíno Rambo S. J.: sacerdote, naturalista, escritor e jornalista (1905-2005). IHU OnLine, São Leopoldo, RS, p. 34-37, 2005. Disponível em: < http://www. unisinos.br/exposicao/images/stories/padre_rambo/pdfs/martin.pdf $>$. Acesso em: fev. 2012.

SANTOS, Eurico. Anfíbios e répteis do Brasil. 3. ed. rev. e ampliada. Belo Horizonte: Itatiaia, 1981. (Coleção Zoologia Brasílica, v. 3).

SANTOS, Eurico. Da ema ao beija-flor: vida e costumes das aves no Brasil. 2. ed. Rio de Janeiro: F. Briguiet, 1952. 
SANTOS, Eurico. Os insetos: vida e costumes. Belo Horizonte: Itatiaia, 1982. (Coleção Zoologia Brasílica, Tomo I, v. 9).

SANTOS, Eurico. Pássaros do Brasil: vida e costumes. 5. ed. revista e ampliada. Belo Horizonte: Itatiaia, 1985. (Coleção Zoologia Brasílica).

SANTOS, Eurico. Peixes da água doce: vida e costumes dos peixes do Brasil. 4. ed. Belo Horizonte: Itatiaia, 1987. (Coleção Zoologia Brasílica, v. 2).

SANTOS, Eurico. Peixes do Brasil. Rio de Janeiro: F. Briguiet, 1952.

SANTOS, Eurico. Proteção à fauna indígena. Rio de Janeiro: F. Briguiet, 1948.

SINGER, Peter. Libertação animal. São Paulo: WMF Martins Fontes, 2010.

STRAUBE, Fernando Costa. Uma visão bio-bibliográfica da natureza brasileira de Eurico Santos: divulgador da natureza brasileira.

Atualidades Ornitológicas On-line, Ivaiporã, PR, n. 148, março/abril 2009. Disponível em: < http://www.ao.com.br/download/ao148_38. pdf $>$. Acesso em: fev. 2012.

THOMAS, Keith. O homem e o mundo natural: mudanças de atitudes em relação às plantas e aos animais (1500-1800). 4. ed. São Paulo: Cia. das Letras, 2001.

VIDA e obra de Pe. Balduíno Rambo S. J. [Exposição]. São Leopoldo, RS: Unisinos, 2005. Disponível em: http://www.unisinos.br/exposicao/ rambo. Acesso em: set. 2011.

Carlos Renato Carola, doutor em História pela Universidade de São Paulo (USP), é professor do Programa de Pós-Graduação em Educação da Universidade do Extremo Sul Catarinense (Unesc), Criciúma, SC, Brasil. Desenvolve pesquisa na área de História Ambiental e Educação.

crc@unesc.net

Gladir Silva Cabral, doutor em Letras (Inglês e Literatura Correspondente) pela Universidade Federal de Santa Catarina (UFSC), é professor do Programa de Pós-Graduação em Educação da Universidade do Extremo Sul Catarinense (Unesc), Criciúma, SC, Brasil. Desenvolve pesquisas relacionadas à identidade cultural, literatura, linguagem e educação.

gla@unesc.net

Recebido em 6 de setembro de 2012.

Aprovado em 26 de março de 2013. 